\title{
The endoscope and instruments for minimally invasive neurosurgery
}

\author{
Salman Shaikh, Chandrashekhar Deopujari \\ Department of Neurosurgery, Bombay Hospital Institute of Medical Sciences, Mumbai 400020, India.
}

Correspondence to: Prof. Chandrashekhar Deopujari, Head of Neurosurgery, Bombay Hospital Institute of Medical Sciences, Room 114, MRC building, Bombay Hospital, 12, Marine Lines, Mumbai 400020, India. E-mail: d.chandrashekhar11@gmail.com

How to cite this article: Shaikh S, Deopujari C. The endoscope and instruments for minimally invasive surgery. Mini-invasive Surg 2020;4:89. http://dx.doi.org/10.20517/2574-1225.2020.97

Received: 6 Oct 2020 First Decision: 5 Nov 2020 Revised: 13 Nov 2020 Accepted: 17 Nov 2020 Published: 10 Dec 2020

Academic Editor: Oreste de Divitiis Copy Editor: Cai-Hong Wang Production Editor: Jing Yu

\begin{abstract}
The advent of neuroendoscopy catalyzed the ongoing development of minimally invasive neurosurgery in the 1990s. This millennium has seen rapid developments in the design of scopes, improved high-definition visualization systems, and a plethora of dedicated instruments. Many minimally invasive and endoscopic procedures have become the new "standard of care" today. Endoscopic third ventriculostomy and endonasal pituitary surgeries have replaced alternative techniques in most major institutes in the world and the indications are rapidly increasing to tackle many midline skullbase, intraventricular, and some parenchymal lesions as well. The scope of minimally invasive neurosurgery has extended to spine surgery, peripheral nerve surgery, and unique indications, viz. craniosynostosis repair. This review describes many of these developments over the years, evaluates current scenario, and tries to give a glimpse of the "not so distant" future.
\end{abstract}

Keywords: Hydrocephalus, endonasal endoscopic approach, minimally invasive neurosurgery, minimally invasive spine surgery, neuroendoscopy, skullbase, ventricular surgery

\section{INTRODUCTION}

Minimally invasive surgery has become the "standard of care" over the last 50 years in various branches of surgery. Although endoscopic neurosurgery for hydrocephalus took roots quite early, it took much longer for the other procedures to develop until the introduction of dedicated scopes and appropriate instrumentation. Endoscopic third ventriculostomy became a real alternative to shunt surgery for 


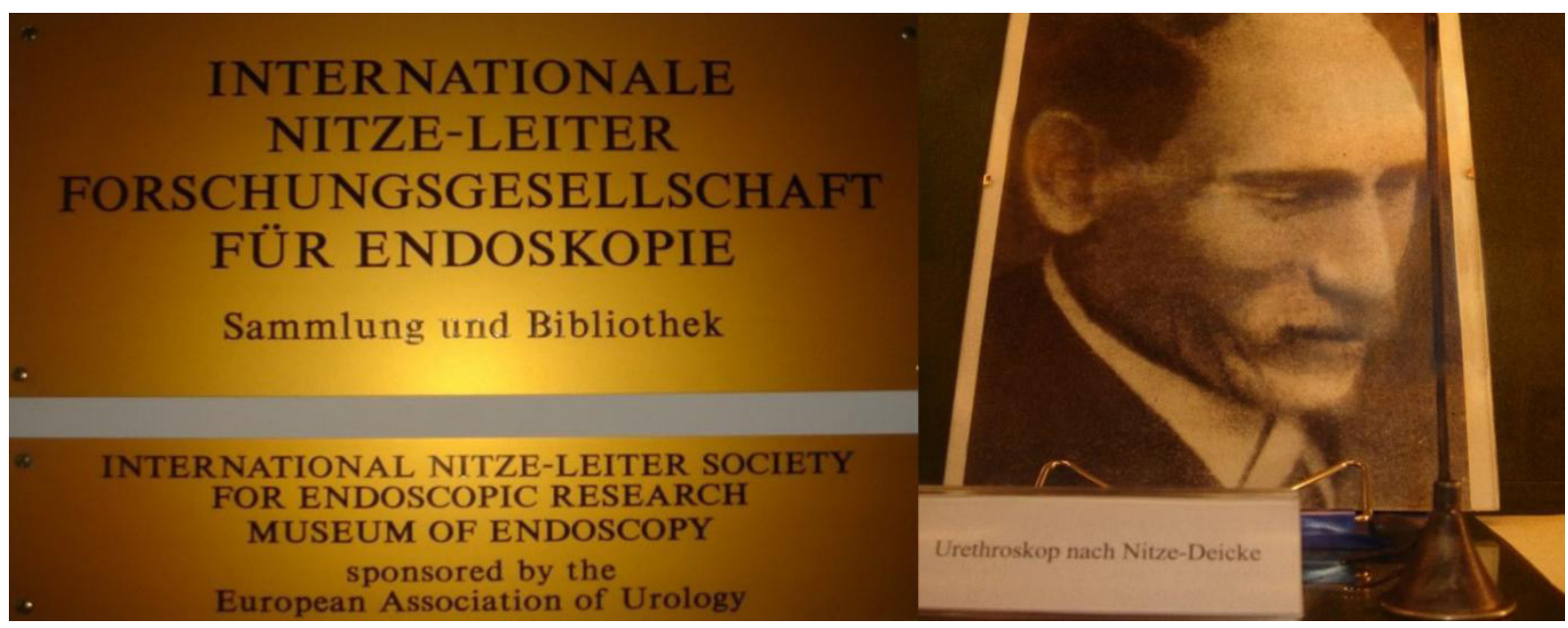

Figure 1. Maximilian Nitze's urethroscope kept on display at the endoscopy museum at Vienna

hydrocephalus only 25 years ago. Its widespread application to intraventricular procedures was the next logical progression. Simultaneously, the popularity of functional endoscopic sinus surgery logically extended to neurosurgery of the skullbase. Tubular retractor systems developed for minimally invasive spinal neurosurgery were then well supported by endoscopy. Endoscopy for minimally invasive neurosurgery can be broadly considered to be of three types ${ }^{[1]}$ : (1) purely endoscopic surgery (channel endoscopy); (2) endoscope guided surgery (endonasal or port surgery); and (3) endoscope assisted microsurgery.

The commonly performed "purely endoscopic procedures" include third ventriculostomy, septostomy, aqueductoplasty, and biopsies. The "endoscopic guided procedures" can be performed purely by endoscopy as well but may require assistance by instruments outside the scope, such as for most endonasal pituitary, skullbase procedures and intraventricular tumors. The "endoscopy assisted procedure" could be any standard microsurgical procedure wherein endoscopy provides special benefits of looking around the corners as in the case of vestibular schwannomas, epidermoid, and various other skullbase surgeries. It also helps in aiding and confirming hemostasis in areas which cannot be easily approached without too much brain retraction. The endoscope and its related accessories/instruments remain the backbone of any of these endoscope-dependent techniques ${ }^{[2,3]}$.

The present paper traces the evolution of endoscopic techniques as applied to neurosurgery and describes the available armamentarium for the aid of neurosurgeons.

\section{DISCUSSION}

\section{Evolution of neuroendoscopy}

The basic principle of endoscopy lies in the illumination and internal reflection of light in a body cavity. This principle has been worked upon by many scientists even before the era of modern medicine. Greek scientist Hippocrates' work published in the book "The Art of Medicine" and Arab-Spanish surgeon Abual-Qasim's techniques from the book "Al-Tasrif" (The Method) are testament to the fact that endoscopy had its origins many years earlier than previously thought ${ }^{[4]}$. For his description and application of the first prototype of an endoscope, German physician Philip Bozzini is widely, albeit contentiously, regarded as the "Father of Endoscopy" ${ }^{[5]}$. The first therapeutic application of endoscopy was in the field of urology in 1873 by Joseph Grunfeld from Austria. This was closely followed by the development of the first direct-vision rigid endoscopes (cystoscope) in 1877 by Maximilian Nitze ${ }^{[6]}$ [Figure 1]. The inbuilt light source system effectively corrected the persistent issues with illumination in the application of endoscopy. 


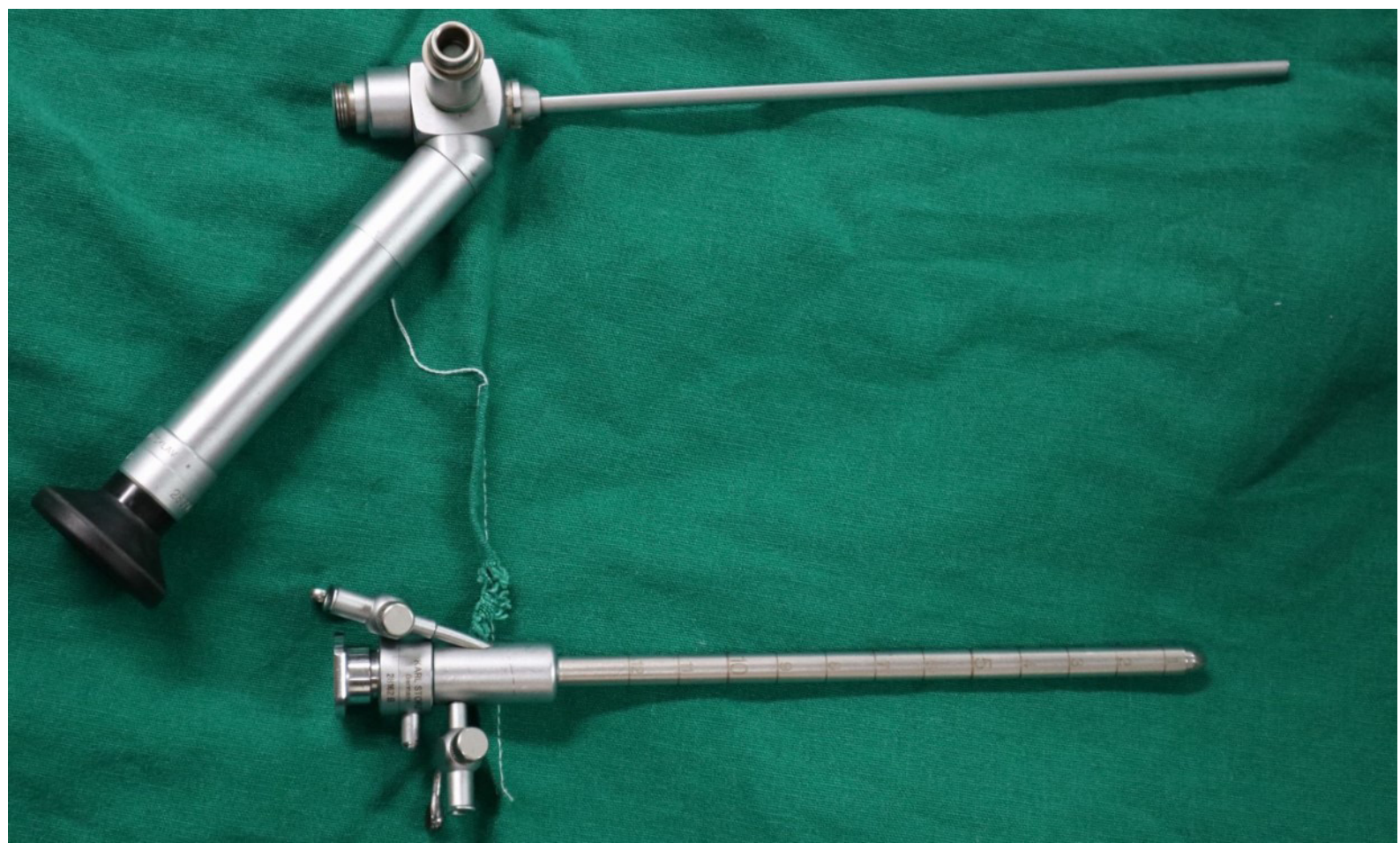

Figure 2. Gaab scope with obturator. The side channel allows ultrasonic surgical aspirator shaft to pass through

The scope system then underwent several technical modifications before being implemented widely in the field of surgery. Victor Lespinasse, Walter Dandy, and William Mixter were the pioneers for introducing endoscopy in neurosurgery. The earliest instruments used for this purpose were cystoscopes and urethroscopes. Use in neurosurgery was therefore limited due to the rigid nature of the instrument, suboptimal optics, and large size of the scopes. Although the term ventriculoscopy was first used by Walter Dandy in 1922 while describing his unsatisfactory experience with a cystoscope, the first ventriculoscope was described a few years later by Tracy Putnam and thereafter perfected by John Scarrf ${ }^{[7]}$.

The major improvement in optical imaging was bought about by renowned British Physicist, Professor Harold Hopkins. He was the foremost authority in his field and is credited for introducing concepts of zoom lens, rod-lens endoscopes, and rigid/flexible endoscopes. The rights to his work on the lens system for endoscope were purchased by Karl Storz SE \& Co. KG from Germany in the 1960s, and, until now, surgeons from the world over are taking benefit of this partnership ${ }^{[8]}$.

Takanori Fukushima from Japan used a fiberscope in 1973 for intraventricular as well as subarachnoid space endoscopic surgery with malleable instruments but the poor picture quality in the fiberscope made it unpopular ${ }^{[9]}$. The introduction of side viewing wide angled lens by Michael Apuzzo ushered in the era of modern neuroendoscopy, an era which would be subsequently based upon a foundation of clarity, illumination, maneuverability, and allowed widespread application. A channel endoscope dedicated to intraventricular neuroendoscopy was initially developed by Michael Gaab from Germany (for Karl Storz) [Figure 2]. Subsequently, additional channels were modified onto a rigid endoscope by Philippe Decq from Paris in 1996 [Figure 3], and it was clinically applied for ventriculocystocisternostomy in suprasellar arachnoid cysts and for purely endoscopic colloid cyst excision ${ }^{[10,11]}$. This enabled simultaneous usage of unipolar or bipolar probe biopsy forcepsalong with suction and irrigation and helped expand the armory of neuroendoscopy by allowing bimanual dissection. 


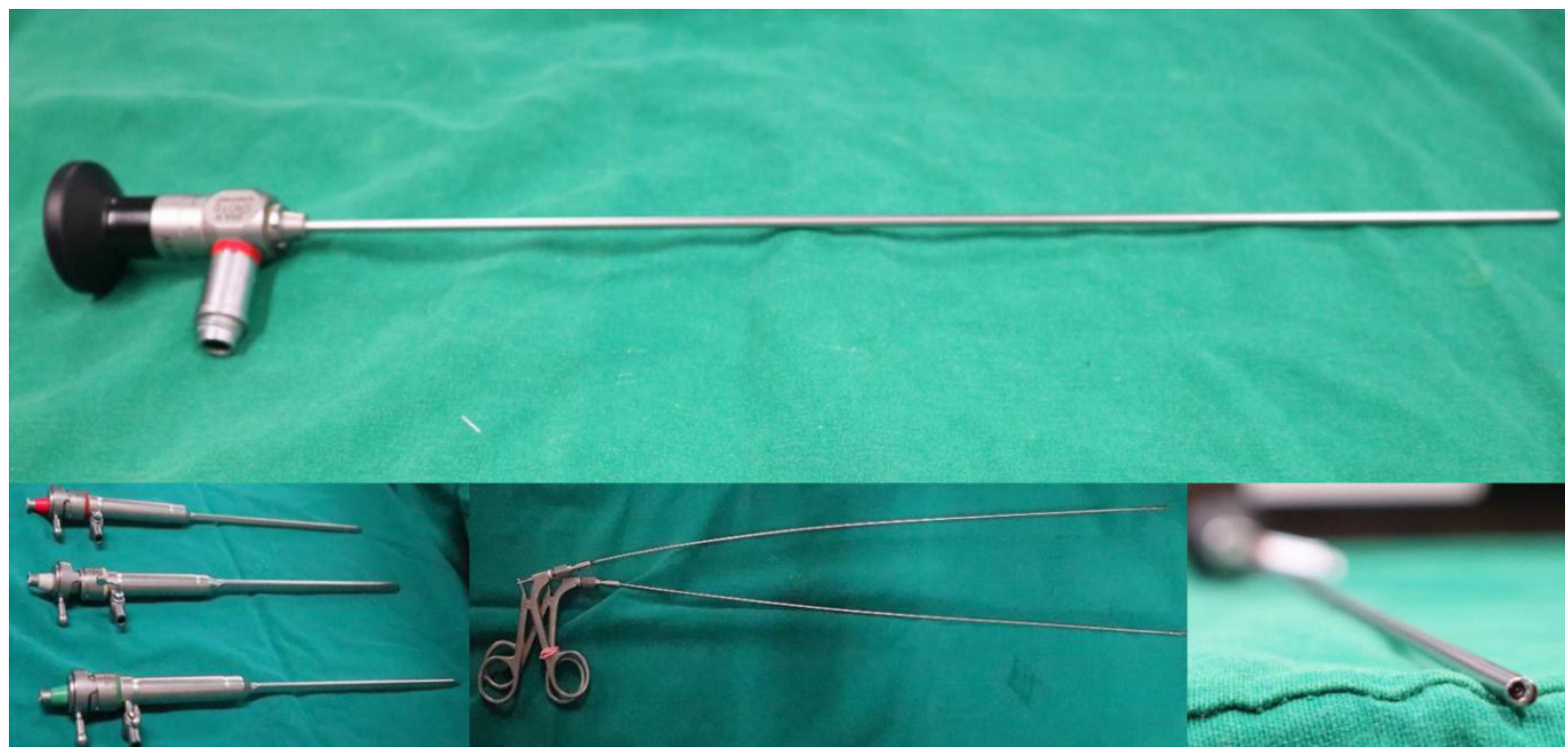

Figure 3. Decq scope and its tip with multiple channels and malleable instruments which can pass through it

\section{Endoscopes and endoscopic procedures}

In the 1990s, Claris Corporation was the first to come out with endoscope guided ventricular catheter placement for treating hydrocephalus ${ }^{[12]}$. These scopes were lightweight, thin with outer diameter of $1.14 \mathrm{~mm}$, and able to be introduced into shunt catheters. Medtronic Company from USA then came out with a similar functioning NeuroPEN endoscope. Correspondingly, slit tip catheters were introduced by Medtronic and Codman (USA) for ventriculoscopic placement. However, they did not attain wide acceptance as the literature consists of experiences mentioning only small case series ${ }^{[13]}$. This was probably due to the absence of any discernible benefit over routine shunt catheter placements ${ }^{[14]}$, relatively higher costs, and suboptimal vision. However, neurosurgeons have not been deterred from probing avenues for further improvements in endoscopic treatment of hydrocephalus ${ }^{[15]}$. The multipurpose ventriculoscope described by Henry Schroeder in 2008 helps in tackling not only obstructive CSF pathways but the extra channel allows also intraventricular lesion biopsy and resection, among other uses ably aided by the then newly developed high definition (HD) visualization and display system ${ }^{[16,17]}$.

Bauer, Hellwig, and their team from Marburg, Germany published their eight years of experience of stereotactic endoscopy ${ }^{[18]}$ wherein they used it for cystic cerebral pathologies, intracerebral hematoma evacuation, brain abscess, third ventriculostomy, and retrieval of ventricular catheters. Axel Perneczky ${ }^{[19]}$ from Mainz, Germany is credited with bringing "minimally invasive neurosurgery" to the mainstream in 1998 by greater use of narrower (MINOP, Aesculap) endoscopes in ventricles and using them for indications beyond hydrocephalus. He brought stereotaxy and navigation guidance in endoscopy to the forefront ${ }^{[20]}$ and developed the concept of "endoscope guided surgery" for cases such as colloid cysts. Endoscope assisted microneurosurgery was the next stage in the mid-1990s and innovations to attain the best dual imaging were highly sought after. Axel Perneczky proposed projection of the endoscopic images into a head mounted LCD device which was not routinely available in that period ${ }^{[1]}$. His most important contribution was the concept of "keyhole surgical approaches" with the integration of these visualization methods to the skullbase and development of specially designed shaft instruments for dissection [Figure 4], clip applicators, and a table mounted endoscope holding device to aid bimanual endoscopic surgery.

Endoscopic third ventriculostomy (ETV) is one of the most widely performed procedures in neuroendoscopy today and its results have been validated worldwide for hydrocephalus ${ }^{[21]}$. Several techniques and 


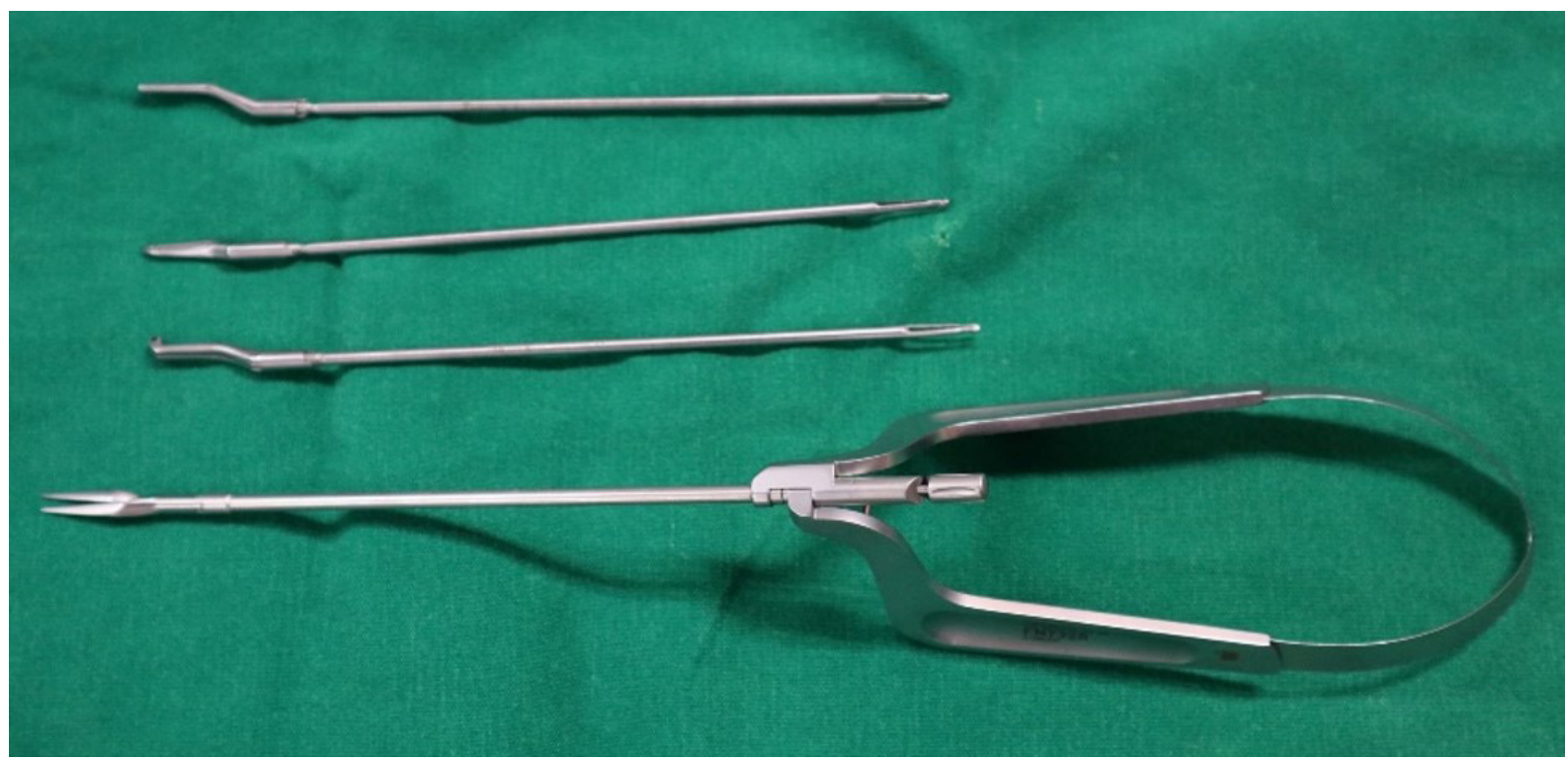

Figure 4. MINOP shaft instrument with multiple attachments

instruments have been described for safe perforation of the ventricular floor and then dilating it, such as with the leucotome, puncturing needle, blunt endoscope, Fogarty balloon, monopolar electrode, wired stone extractor, etc. ${ }^{[22]}$. Andre Grotenhuis from the Netherlands designed an endoscopic perforator which sucks and lifts the floor before forceps can be introduced to widen the opening ${ }^{[23]}$. This reduces the chances of basilar artery damage during ETV. Success score systems predicting ETV's outcome in adult and pediatric patients ${ }^{[24]}$ and other criteria for defining its prognosis have been well explained in the literature ${ }^{[25]}$. ETV has also been attempted via a flexible scope through the lamina terminalis in cases of technical difficulty to perforate the floor via traditional route ${ }^{[26]}$. Endoscopic biopsy has also been favorably evaluated $^{[27]}$, and occasional resections of tumors are being reported by many centers ${ }^{[28,29]}$.

The first series of cases published of endonasal transsphenoidal approach was by Jankowski et al. ${ }^{[30]}$ from France who presented his experience in three cases of pituitary adenomas in 1992. Subsequently, Jho and Carrau ${ }^{[31]}$ from the University of Pittsburgh, USA successfully used nasal endoscopes for transsphenoidal pituitary surgery and published the first large series of 50 patients in 1997. Immediately following that, the concept of functional endoscopic pituitary surgery was mooted by Cappabianca et al. ${ }^{[32]}$ in 1998 from Naples, Italy, which gave a big push forward to endonasal surgery. Thereafter, the preference shifted to the more versatile binostril approach, especially after very good results of 800 cases were put forward by Kassam et al. ${ }^{[33]}$ from USA. Gradually, extended approaches to pathologies of the skullbase came to the fore with the improvement in skullbase defect repair techniques ${ }^{[3,35]}$.

A dedicated pediatric endoscope was developed by Oi et al. ${ }^{[36]}$ from Japan for Karl Storz (Oi Handy Pro endoscope). This system had a smaller working diameter and a 2-mm lens with malleable instruments and a pistol grip for easier holding [Figure 5]. It provides a narrower tract which is extremely important in infants and small children, not only to minimize brain damage but also to reduce the occurrence of postoperative CSF leaks. It is also recommended in cases where the foramen of Monroe is not large enough for safe passage of the larger adult scope.

Pediatric Lotta system from Karl Storz was conceptualized by Henry Schroeder who developed this HD visualization scope with narrow shaft and another one with a wider shaft for adults with an extra channel that can take in two instruments through two channels of the scope apart from the suction-irrigation port 


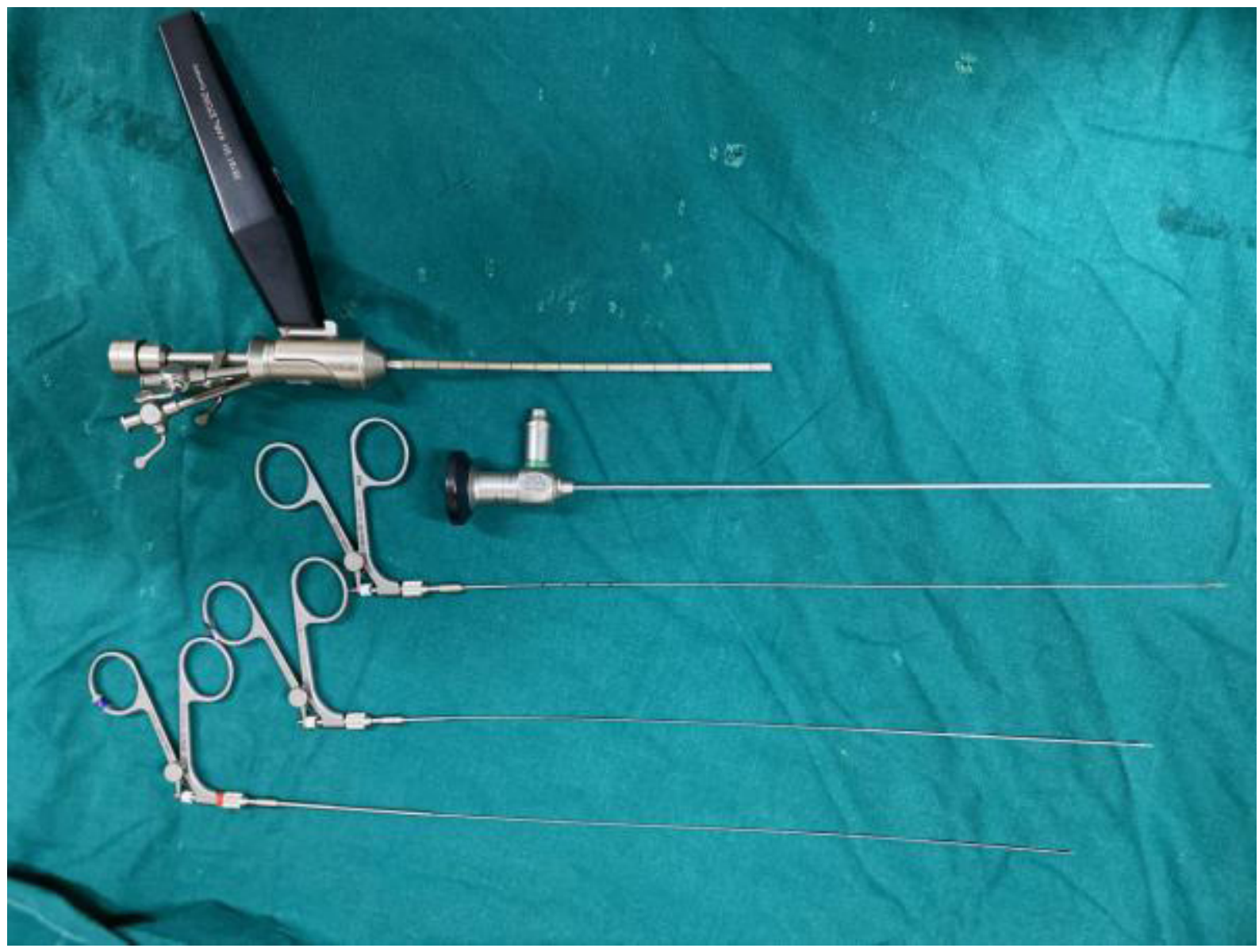

Figure 5. Oi scope with malleable instruments and pistol grip handle

[Figure 6A]. This system also has an optical obturator for scope insertion under visualization [Figure $6 \mathrm{~B}]^{[37]}$. Parallel developments in rigid endoscope were also undertaken by other companies such as Wolf from USA, Rudolf from Germany, and Olympus and Machida from Japan. The use of HD visualization has greatly improved accuracy of endoscopic neurosurgery and the recent introduction of $4 \mathrm{~K}$ display system is a big stride forward in better visualization. Experience with 3D-HD endoscopy has slowly started gaining momentum in the field of neurosurgery. As compared to the traditional $2 \mathrm{D}$ display, 3D system provides a better depth perception especially for those neurosurgeons starting out in this field ${ }^{[38]}$. This has still not come in wider use because of limited availability and much higher costas well as due to the familiarity of most experienced neurosurgeons with dynamic endoscopy and 2D HD systems. Although this review focuses mainly on cranial endoscopy, a brief overview of spinal endoscopic system is given. One of the earliest innovators in spine endoscopic surgery was Destandau ${ }^{[39]}$ from France. By using the ENDOSPINE System (Karl Storz, Germany), he first described his technique for endoscopic discectomy in 1999, which is currently a widely practiced method. A versatile SMART endoscopic spine system was put forth by Chiu ${ }^{[40]}$ in 2006 with a wide variety of applications, viz. degenerative spine disease, spinal fixation, discectomy, etc. In 2007, Oertel et al. ${ }^{[41]}$ described the "EASY GO" system for spinal endoscopy consisting of dilators of varied sizes, sheaths, 30-degree endoscope, and endoscope holder. This system does not have a long learning curve and has been shown to have excellent postoperative response as per feedback of over $80 \%$ of patients. 


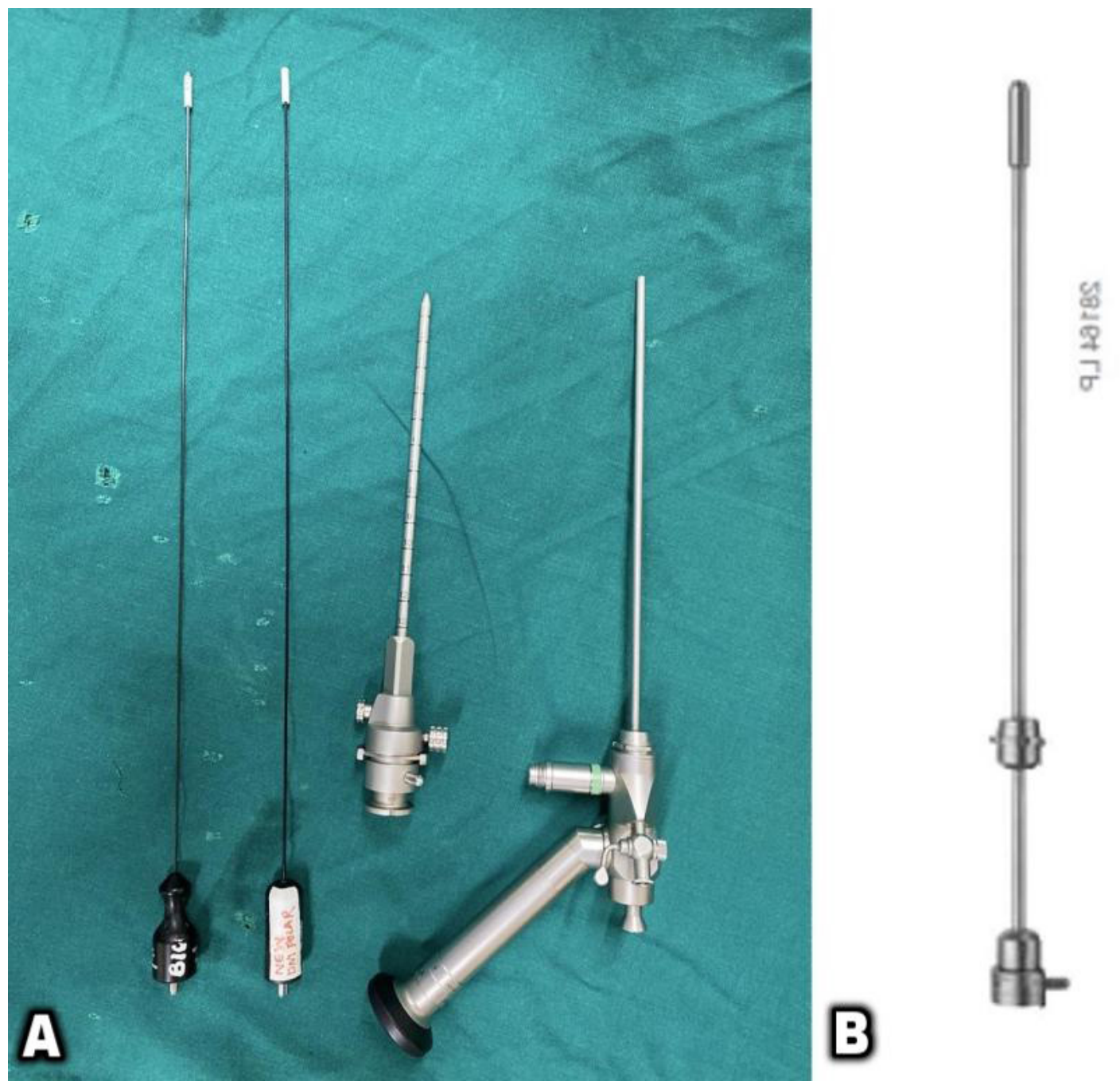

Figure 6. A: Lotta scope with ceramic bipolar; B: optical obturator for guided insertion

\section{Endoscopic accessories}

\section{Irrigating sheaths for endonasal procedures}

To improve visibility further and to tackle issues such as fogging in a better manner, lens cleaning devices and irrigating sheaths [Figure 7] were introduced by Cappabianca et al. ${ }^{[42]}$. Although it may be extremely useful for better uninterrupted vision, especially without a good assistant, the increased outer diameter of the scope shaft with the sheath does not allow ease of instrumentation. We have favored dynamic endoscopy with manual irrigation. However, there are strong proponents of its use, e.g., Prof. Locatelli et $a l .{ }^{[43]}$ with the forceful irrigation method called "diving technique". This not only improves irrigation but also washes away debris forcefully and helps in developing better tissue planes by hydrodissection (waterjet method).

\section{Endoscope holders}

Endoscope holders add to the comfort and ease of the surgeon in endoscopy and help to free the operating hands [Figure 8]. The three types of holders available are rigid non-pneumatic (Aesculap), semi-rigid (Karl Storz), and pneumatic holders (Mitaka, USA) ${ }^{[12]}$. The endoscope holders restrict your field of view and may be used for a small focused area of surgery, viz. ETV. However, the dynamic endoscope movement allows almost $3 \mathrm{D}$ visualization in endonasal approach, and hence holders are not preferred in that surgery. The 


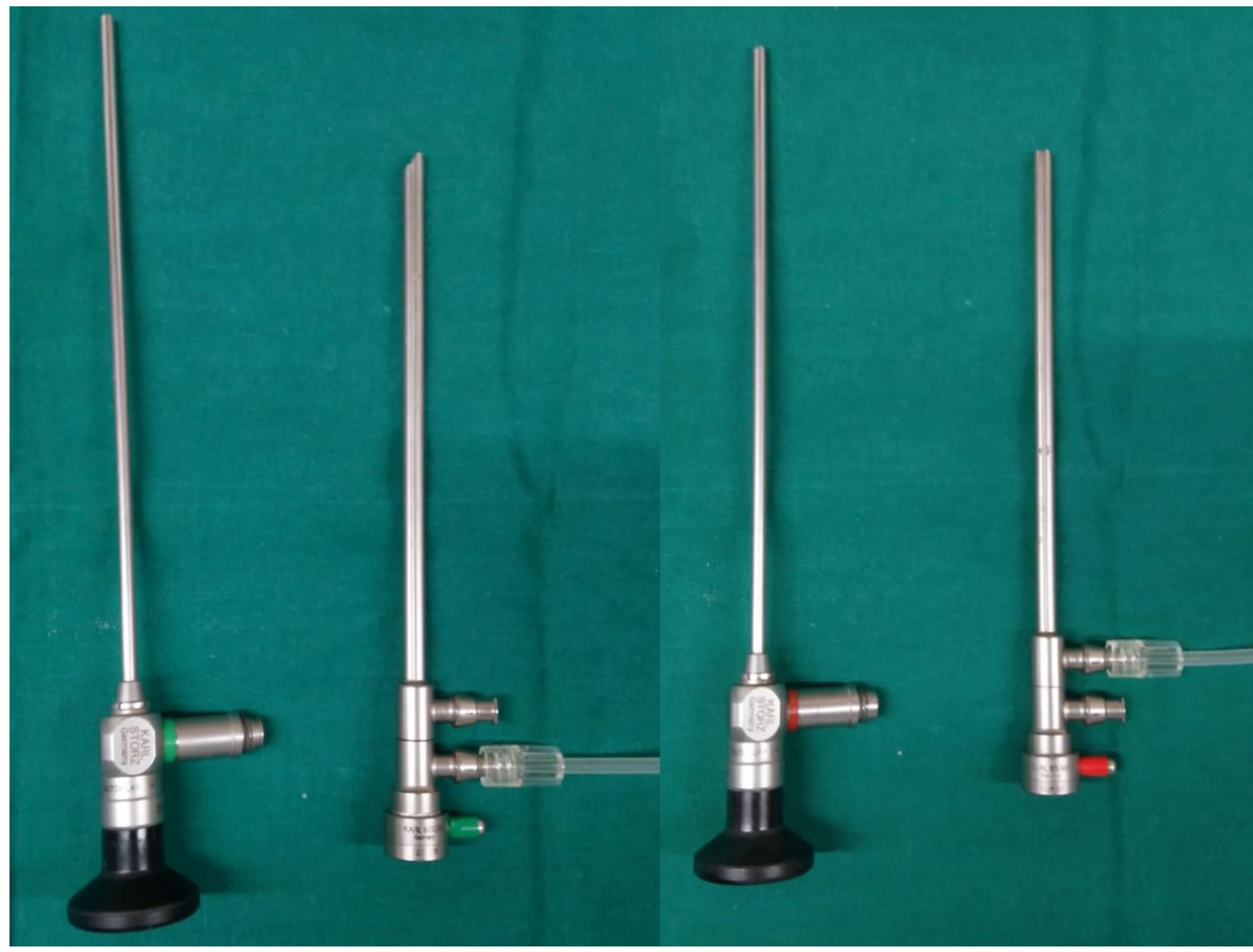

Figure 7. Nasal scope with irrigating sheath

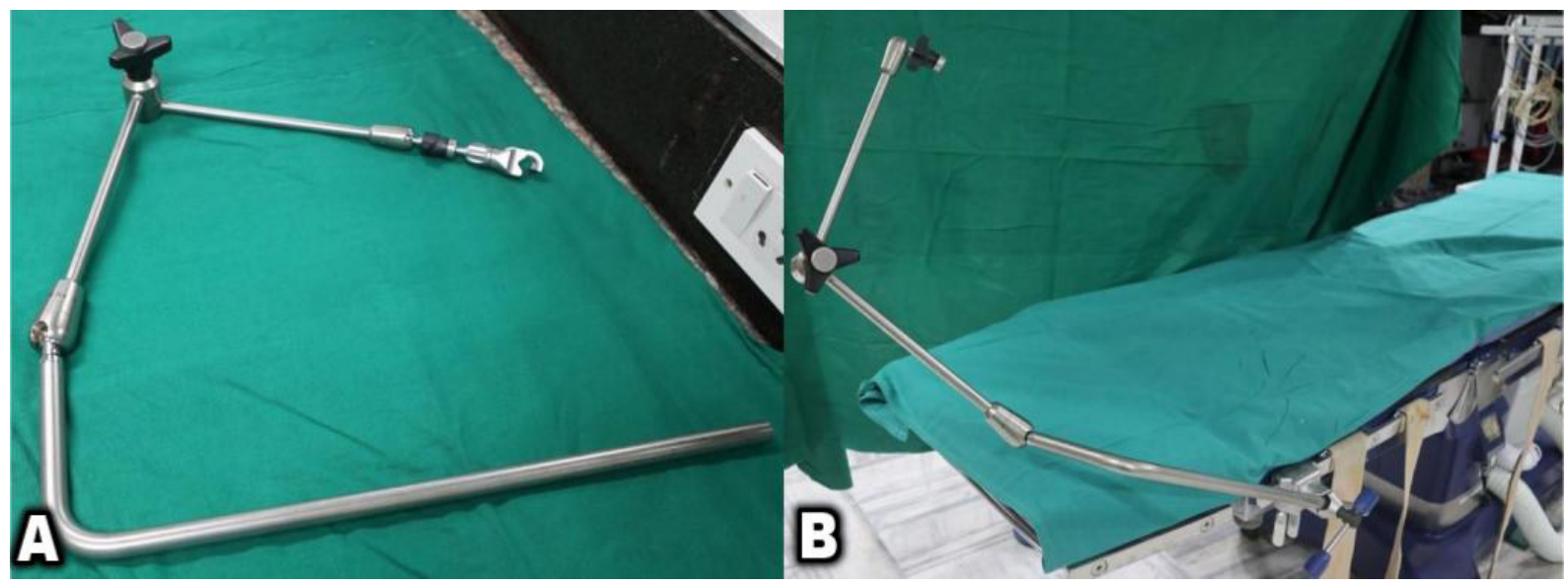

Figure 8. A: free endoscope holder; B: holder attached to the operating table

use of micromanipulator and holder with navigation may allow for fine controlled endoscope movement, as described by Lekovic and Rekate et al ${ }^{[44]}$ in transventricular surgery for hypothalamic hamartomas.

Some of the other technological advances which have helped facilitate endoscopic surgeries include LASER, endoscopic ultrasonic surgical aspirators, neuronavigation, ultrasound probes, tubular retractors, bone ultrasonic surgical aspirator, robotic systems, and special drills. 


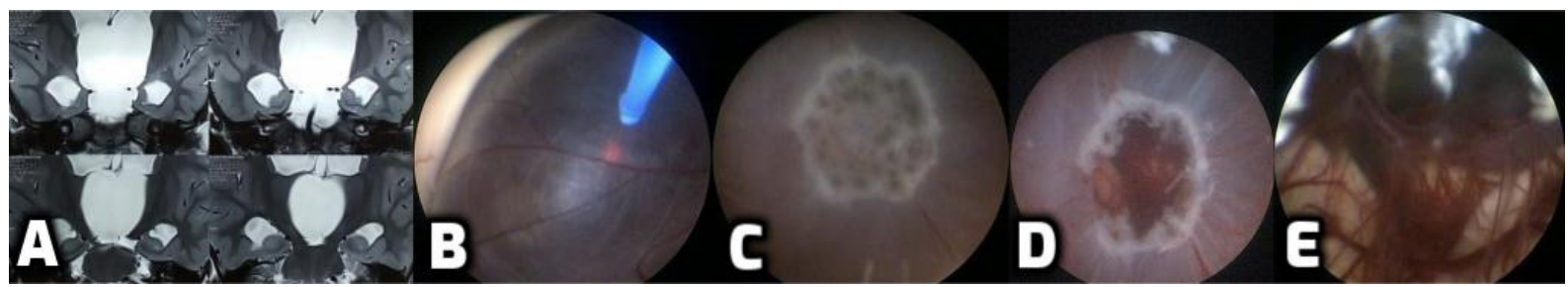

Figure 9. A: MRI T2W coronal section of giant suprasellar arachnoid cyst; B: coagulation of cyst wall by utilizing thulium LASER endoscopically; C: cyst wall after application of the LASER; D: perforated cyst wall; E: intracystic visualization after ventriculocystostomy

\section{LASER}

LASER application in neuroendoscopy has gradually evolved from the initial use of Nd:YAG and KTP LASERr ${ }^{[45,46]}$ to the more recent introduction of Thulium [Figure 9], considered to be more precise and efficacious than its predecessors. Hypothalamic hamartoma disconnection by using thulium represents a good example of LASER replacing the conventional coagulation technique in neurosurgery ${ }^{[47]}$. To combat the issues of damage to healthy brain tissue, LASER now consists of pretreated, carbon coated, diode fiber tip to prevent deeper neurovascular structures from getting damaged with the dissipating energy ${ }^{[48]}$.

\section{Ultrasonic aspirator}

Results of endoscopic ultrasonic aspirator use were first published in 2008 by Oertel et al ${ }^{[49]}$. Since then, it has been used for intraventricular [Figure 10] and paraventricular lesions along with thulium LASER for hemostasis ${ }^{[50]}$. For endonasal surgeries, special thin and long tip ultrasonic aspirators can be used (Both ultastrasonic aspirators by Soering, Germany). We have found ultrasonic aspirators to beuseful but severe limitation can be faced due to repeated blockages and because it can only be used presently with Gaab endoscope channel. Barrow Institute from Arizona, USA introduced a variable aspirator and described its use for endoscopic resection of hypothalamic hamartoma in $2006^{[44]}$. Numerous case series have since described the utility of a multipurpose side cutting aspirator (NICO, Myriad, USA) in neuroendoscopy especially in patients with intraventricular tumors ${ }^{[51-54]}$.

\section{Navigation}

Image guidance in neuroendoscopy has become a vital tool for planning and trajectory guidance [Figure 11] and has been proven to add value to some if not all procedures ${ }^{[55]}$. A global survey of 235 neurosurgeons in $2012^{[56]}$ found that image guidance was used always in conjunction with intraventricular endoscopy by approximately $17 \%$ of participants, especially for tumor biopsy, resection, and cyst fenestration. When it came to endoscopic skullbase surgery, image guidance was used for all cases by $24 \%$ of respondents, and more so for recurrent and complex skullbase anatomy cases. Navigation has also been effectively combined with virtual endoscopy, i.e., magnetic resonance ventriculoscopy, to help reduce chances of damage to critical structures during endoscopic surgery ${ }^{[57]}$. Technically, the tool has advanced over years by overcoming the initial shortcoming of head fixation considered imperative for many years to achieve accuracy. There has since been development of navigation system with face mask (Stryker) and electromagnetic system by companies such as Medtronic, Brainlab, etc. Neither system requires the head to be fixed with pins during surgery. Today, neuronavigation also plays a significant role in simulation training for endoscopy in cadavers as well as synthetic models ${ }^{[58,59]}$.

\section{Ultrasound}

Ultrasound for navigation guiding neuroendoscopy procedures was described as early as the $1990 \mathrm{~s}^{[60,61]}$. This can be very useful if a child has an open fontanelle and is undergoing endoscopic treatment for complex hydrocephalus or multiloculated cysts [Figure 12] and is effectively used by many surgeons as an alternative to MR guided procedures ${ }^{[62]}$. Intracranial application of ultrasound probes concurrent with 


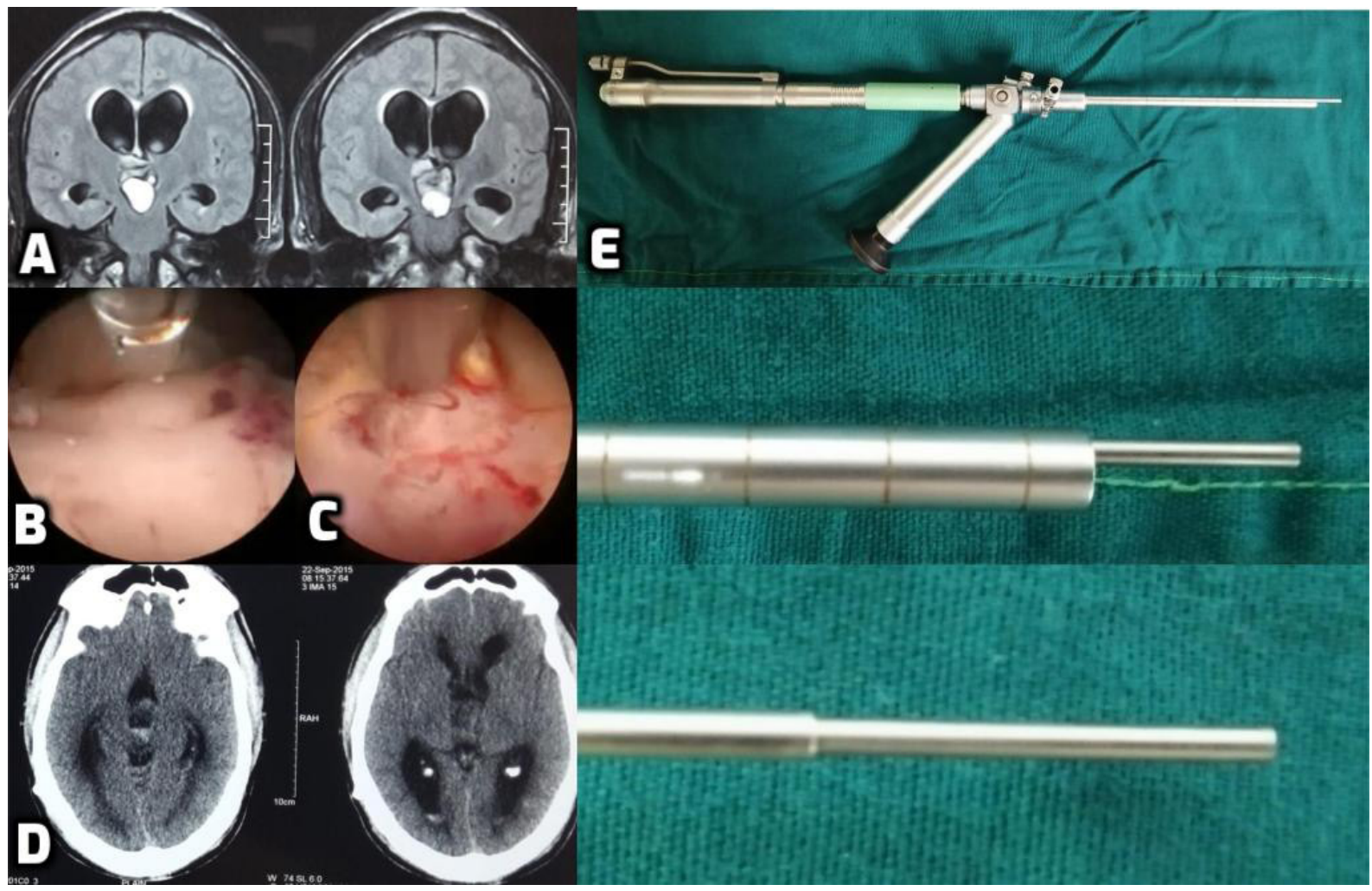

Figure 10. A: MRI FLAIR coronal section of an intraventricular solid cystic pilocytic astrocytoma; B: endoscopic view of the tumour; C: ultrasonic surgical aspirator applied for excision of the lesion; D: postoperative CT scan after gross resection of the lesion via endoscopic approach; E: ultrasonic surgical aspirator instrument with zoomed image of the tip

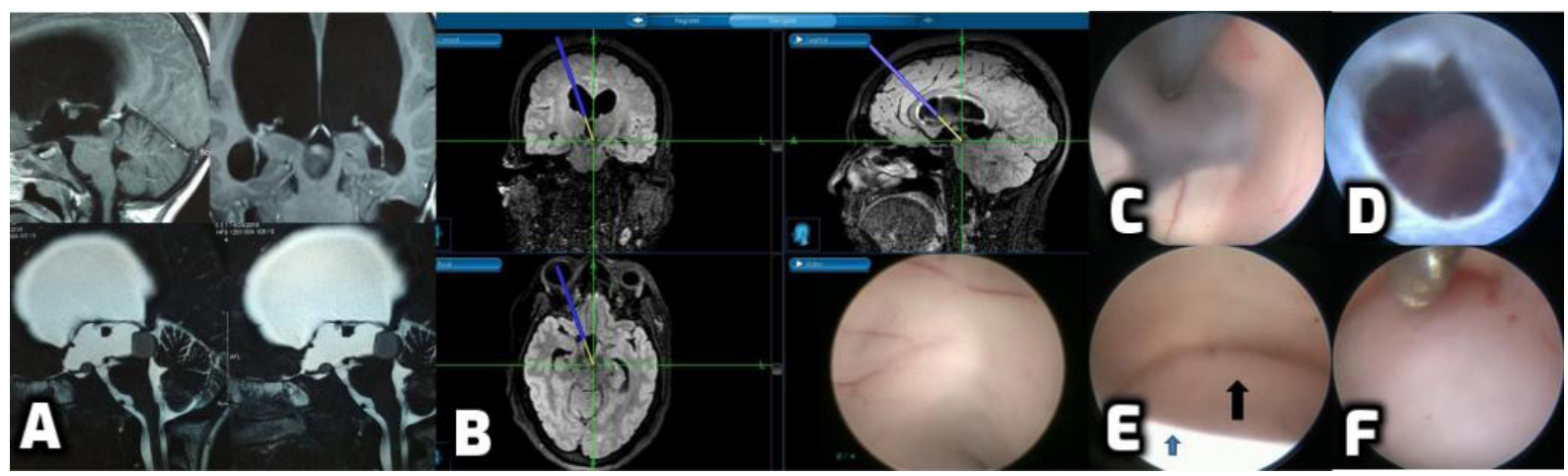

Figure 11. A: MRI (post contrast and T2WI) of a five-year-old child with pineal lesion and hydrocephalus; $\mathrm{B}$ : use of navigation to help in planning the trajectory intraoperatively; C: endoscopic third ventriculostomy done; D: basilar artery seen through the flapping ventriculostomy site; E: tumour (black arrow) seen anterior to the massa intermedia (blue arrow); F: the scope was negotiated below the massa intermedia to reach the tumour for biopsy

endoscopy has been described for hematoma evacuation, biopsies, ventriculostomies, etc. ${ }^{[63-65]}$. Doppler technology of ultrasound has also been used in endoscopic surgeries to indicate presence of surrounding fine vascular structures, thereby increasing the safety profile of endoscopy ${ }^{[66]}$. The utility of Doppler in endonasal surgeries, especially for invasive tumors, recurrences and extended procedures can be gauged by its widespread usage at several centers for lesions with intracavernous extension and carotid encasement ${ }^{[67]}$. 


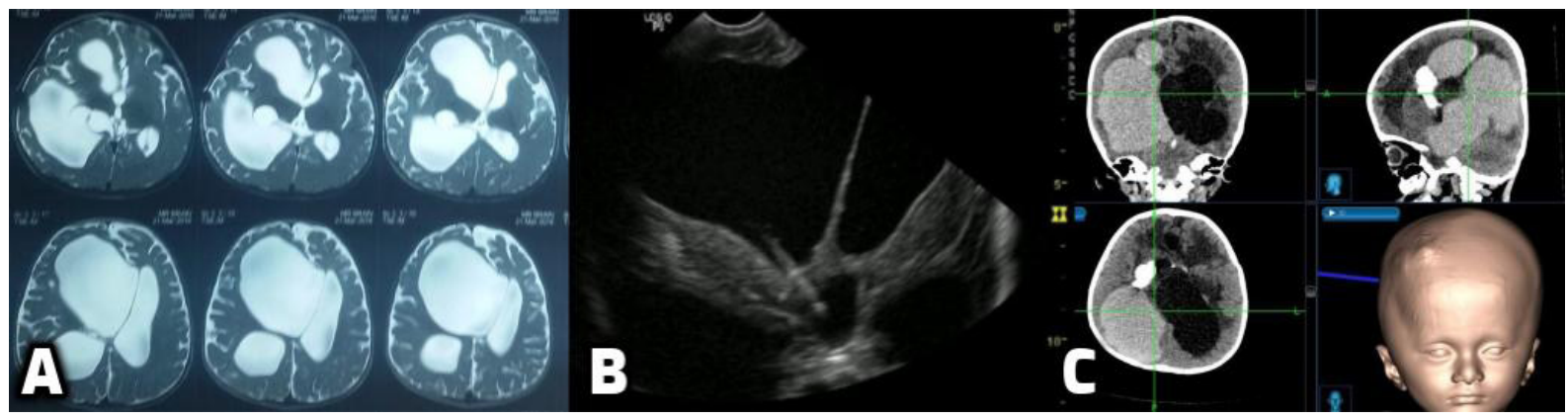

Figure 12. A: MRI T2W axial section showing multiloculated hydrocephalus; B: ultrasound image for guidance of septostomy; C: navigation image showing successful septostomy with passing of catheter to the opposite ventricle

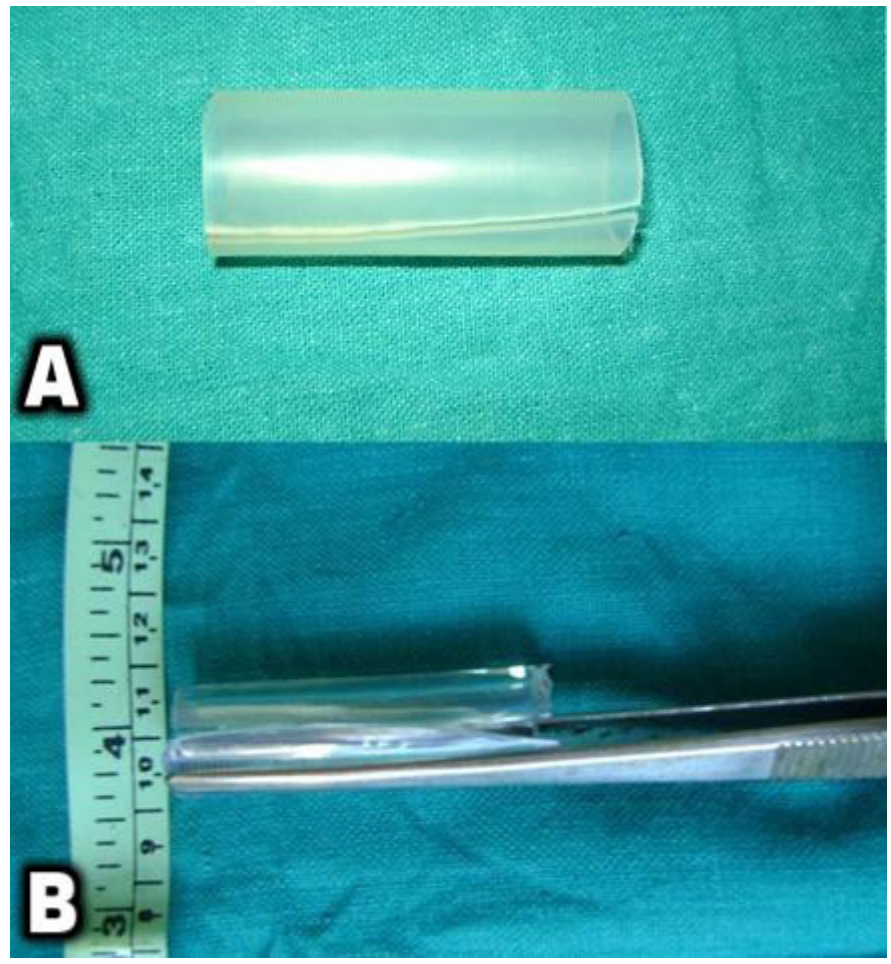

Figure 13. A: the tubular retractor designed by Yadav et al. ${ }^{[70]}$ in 2011. Longitudinal cut allows the retractor to be folded onto itself; B: the small size prevents a large cortical opening

\section{Retractors}

Tubular retractors represent another avenue of augmenting the minimally invasive nature of neuroendoscopy. For intraventricular lesions, a transparent cylindrical port was developed by Daniel Prevedello, Amin Kassam, and their group ${ }^{[68]}$. Many series have been published elaborating on transparent sheath retractor use for ventricular tumors including syringe ports ${ }^{[69]}$. We have used simple transparent tubes for some years now for deep seated lesion excision, while Yadav et al. ${ }^{[70]}$ used it with a small slit to reduce pressure on surrounding brain [Figure 13]. Tubular retractors have also been modified for use as a nasal retractor in skullbase endoscopic surgery ${ }^{[71]}$. Even though the field of vision is proven to be better with microscope assisted surgery than neuroendoscopy ${ }^{[72]}$, many surgeons still favor these retractors.

\section{Hemostats}

Hemostasis aiding endoscopic surgery still relies greatly on conventional and long existing methods such as copious warm irrigation, absorbable gelatin sponges (Gelfoam from Baxter), and oxidized regenerated 


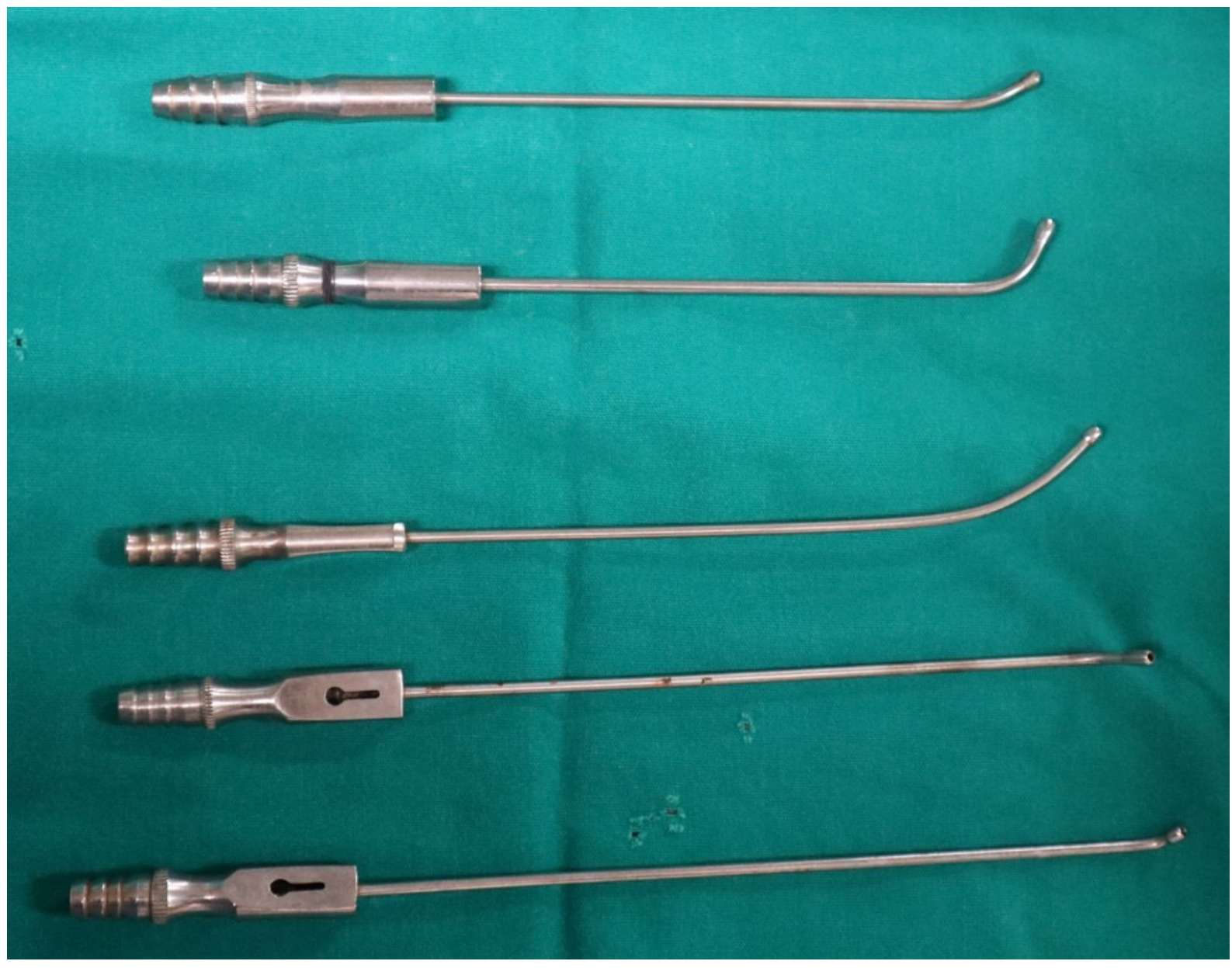

Figure 14. Angled suction tips for cavernous sinus and other areas

cellulose (Surgicel from Ethicon). Newer hemostats have also been introduced with proven benefit in neuroendoscopy such as fibrin sealant (Tisseel from Baxter, Evicel from J\&J) and gelatin-thrombin matrix sealant (FloSeal from Baxter) ${ }^{[73,74]}$.

\section{Specialized instruments}

Ergonomically designed instruments for endonasal surgeries include concealed retractable knife, rotatable scissors for dural incision, curved keyhole and non-keyhole graded suctions, disc dissectors, fine dissectors, ring curettes of varying angles for tumor separation, and pistol grip endoscopic bipolars which can be rotated to adjust the axis of the distal cauterizing tips into a horizontal or vertical plane. Neurosurgeons contributing with instruments for facilitating skullbase endoscopy include Amin Kassam's specialized bipolar and suction device ${ }^{[75]}$ and Paolo Cappabiancas' retractable knife. We have developed our own angled suction sets [Figure 14], malleable keyhole suction and malleable silver dissector [Figure 15], curettes [Figure 16], and bipolar forceps without sliding movement [Figure 17], as shown in Figures 15-17.

\section{Shuntoscope and new fiberoptic scopes}

Semi rigid shunt scope systems [Figure 18] by Karl Storz, Germany have been shown to achieve a more accurate catheter placement, especially in pediatric patients with slit ventricles ${ }^{[76]}$. The next generation fiberoptic neuroendoscopy with "chip on tip" camera combines the best of both flexible and rigid scopes. They were originally developed for bronchoscopy and provide excellent visualization and flexibility to work in the lamina terminalis, temporal horns, fourth ventricle, etc., which are not easily accessible by rigid 


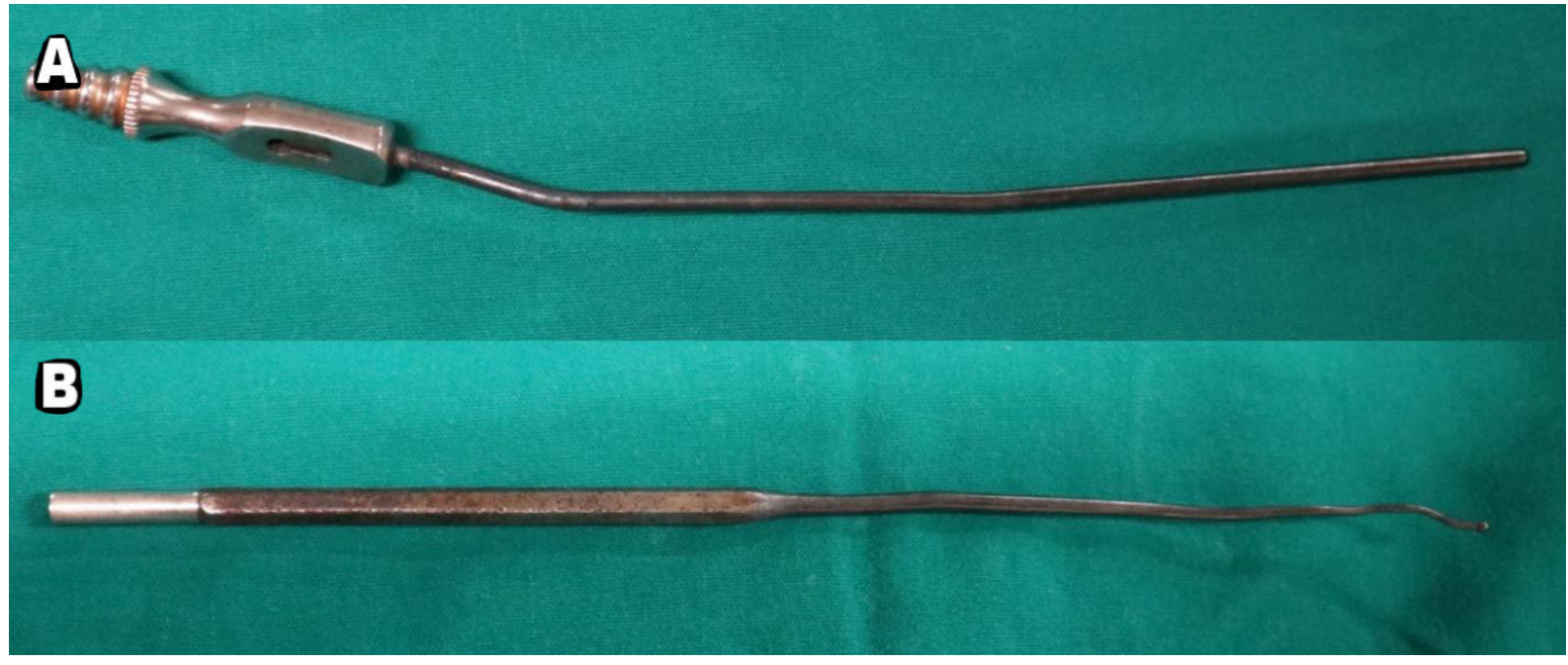

Figure 15. A: malleable keyhole suction; B: malleable silver tipped dissector

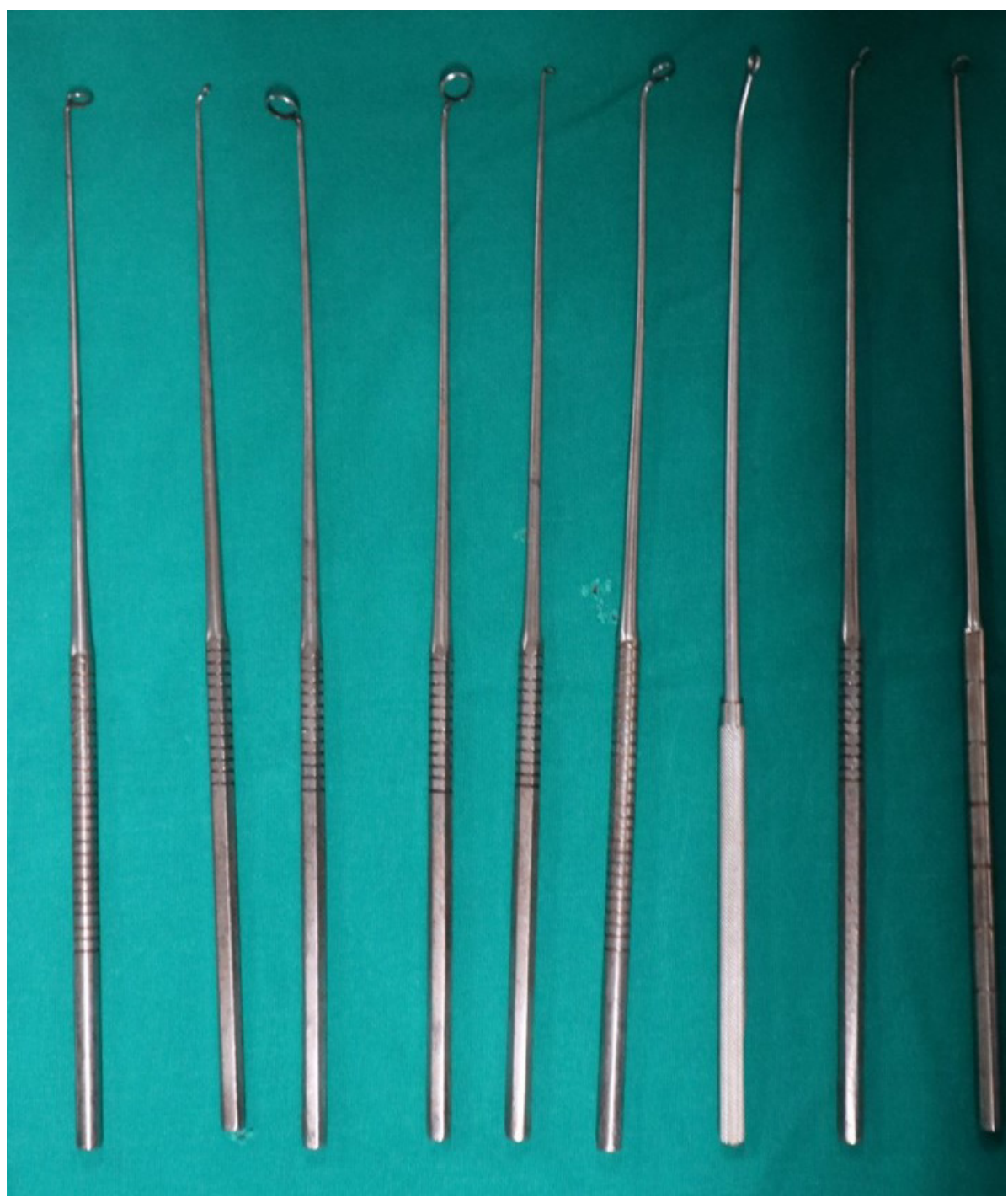

Figure 16. Curettes with various angled tips 


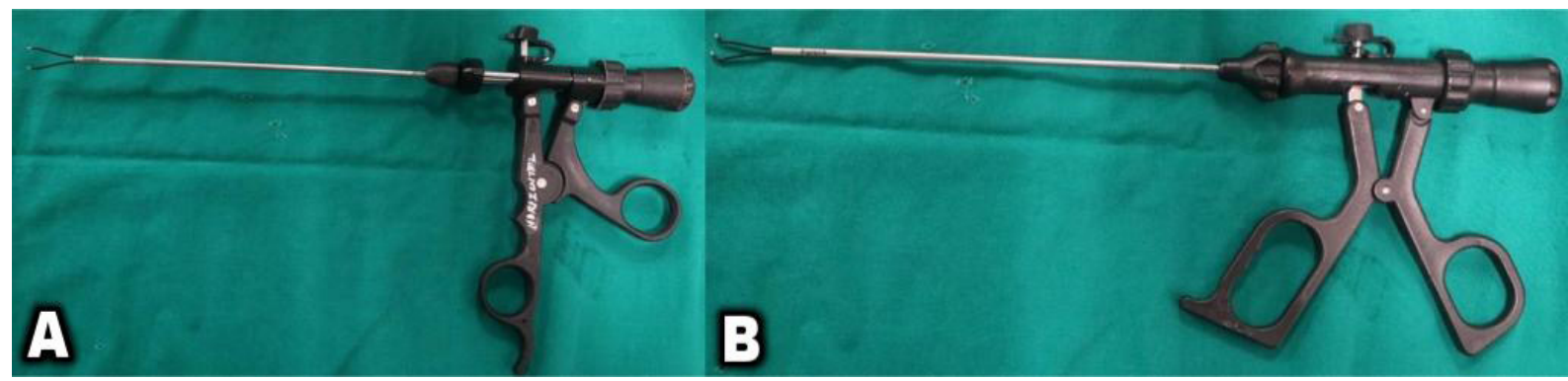

Figure 17. A: bipolar forceps with horizontal tip; B: bipolar forceps with vertical tip

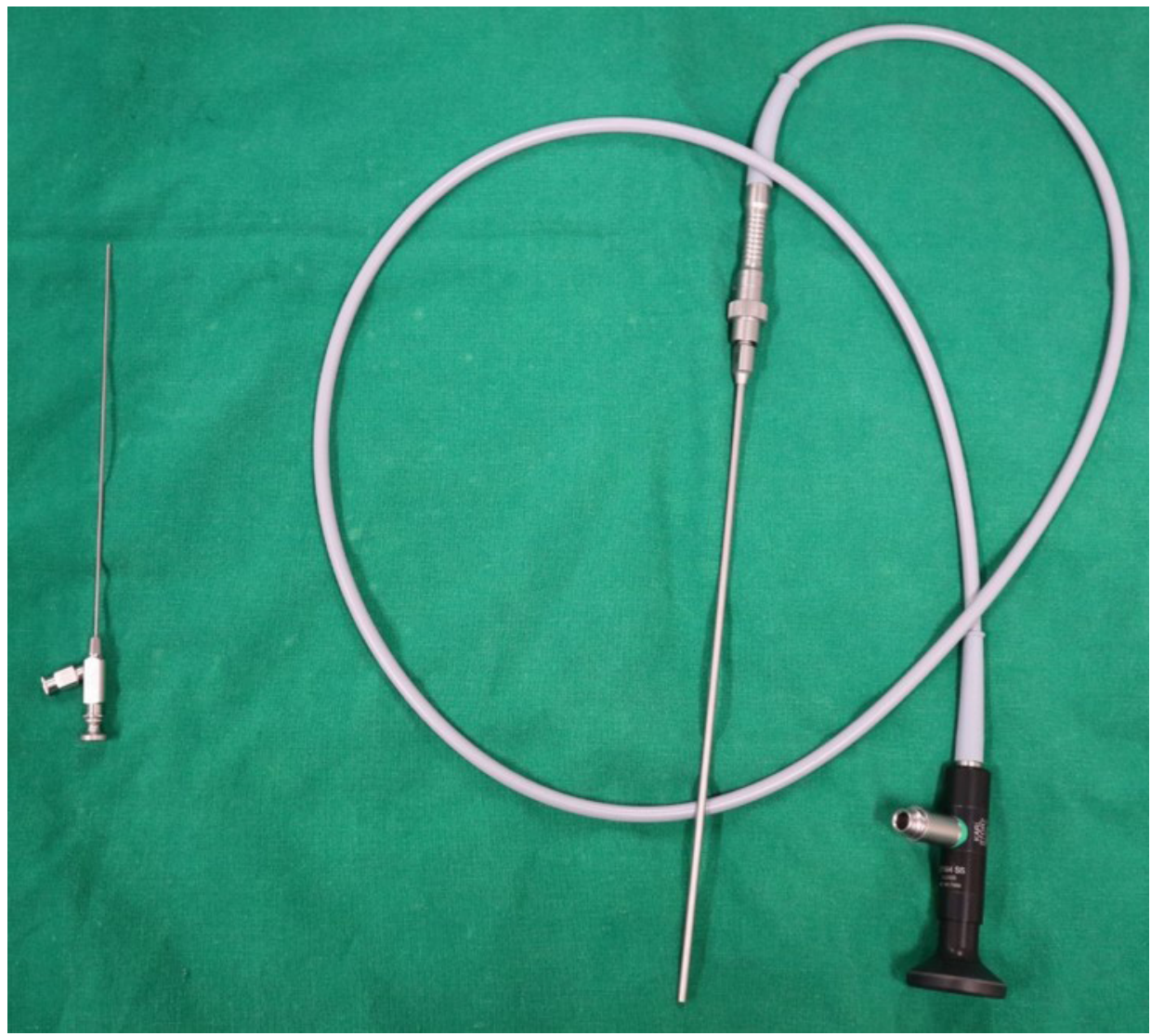

Figure 18. The shuntscope system

scope ${ }^{[77]}$. Currently, they are more expensive than the traditional rigid endoscopes, and there have been reports of visual and electrical interference when used concurrently with monopolar cautery ${ }^{[78]}$. There is also the problem of their sterilization process to ensure safety.

\section{Scope and potential}

Today, the scope of endoscopy has expanded to craniosynostosis repair ${ }^{[79]}$, carpal tunnel release (where it has been found to reduce the immediate postoperative pain as compared to open surgery ${ }^{[80]}$, and endonasally for clipping suitable aneurysms such as unruptured paraclinoid, anterior communication artery, and basilar apex aneurysms ${ }^{[81]}$. A crucial role played by endoscopy in vascular surgery is inspection behind the aneurysms to see origin of a hidden branch or important perforators increasing safety of clipping and assuring a complete clipping. 


\section{Robotic Neuroendoscopy}

The first application of robotic systems in neuroendoscopy was in 2002 by Zimmermann et al. ${ }^{[82]}$ when they successfully used Evolution 1 robot for navigated robotic neuroendoscopic procedures in three patients. Since then, the robotic stereotactic assistance system has been used at many institutions for endoscopic third ventriculostomies, among other procedures ${ }^{[8,84]}$. Robotic guidance systems will eventually provide greater precision, vision, and stability in neuroendoscopy ${ }^{[85]}$. However, as of today, the primary practical role of robotics in neurosurgery is of visualization, to add greater degrees of freedom onto the existing rigid endoscopes along with providing navigation modality for procedures such as biopsies. The surgical component of neuroendoscopy remains under manual control.

Going ahead, it seems almost inevitable that smartphones may soon play an important adjunct role in neuroendoscopy given their widespread availability and uniformity in the operating systems. They have already been touted to replace the video screen system once deemed to be essential along with the endoscope set ${ }^{[8]}$. By amalgamating the light source and camera into a single cable and by reducing the overall weight of the traditional endoscope, Karl Storz came out with a prototype multifunctional videoendoscope which can effectively be used as a single-handed instrument with ease ${ }^{[87]}$. Early results are encouraging in terms of both navigating the instrument and the high-definition images it provides.

A contemporary classification has been proposed in the last few years for endoscopy in minimally invasive cranial neurosurgery taking into consideration its vast application and potential. The procedures can now be grouped as "intraendoscopic" or "extraendoscopic" based on the relation of surgical exercise with the axis of the endoscope ${ }^{[88]}$. This expands the scope of MIS beyond the traditionally defined realms.

\section{Training models and programs}

Currently, many training modules have come to the fore providing young neurosurgeons with experience and practice of life-like clinical scenarios. Apart from computer graphics helping ventricular and endonasal surgeries, synthetic models have also been developed which have been proven to improve hand-eye coordination in endoscopy and reduce the training curve usually associated with it ${ }^{[89]}$. We have developed a model for ventricular surgery which has been very popular with the young trainees ${ }^{[90]}$. Skullbase endoscopy training, however, is best served with cadaveric training and such courses are being regularly held at several conferences, universities, and training centers [e.g., University of Pittsburgh, USA, and Center of Excellence for Minimal Access Surgery Training (CEMAST), Mumbai, India], etc.

\section{CONCLUSION}

Neuroendoscopy is integral to development of minimally invasive neurosurgery. Apart from development of alternative procedures such as endoscopic third ventriculostomy, which have become standard of care, its use has become widely prevalent in transsphenoidal pituitary surgeries as well. It has also opened the doors for extended procedures in skullbase tumors and ventricular tumors. With time, the use of smartphone navigation, robotic applications, and exoscopes in endoscopy will augment the existing armamentarium in neuroendoscopy. Further advances in visualization methods will guide future progress of minimally invasive neurosurgery.

\section{DECLARATIONS}

\section{Acknowledgments}

The authors would like to acknowledge the help of Dr. Aliasgar Moiyadi in reviewing the manuscript. The authors would like to acknowledge the contribution of Dr. Gaurav Gupta, Dr. Varun Thareja, Dr. Kalp Shandilya, Karl Storz SE \& Co. KG and Aesculap, Inc. in collating the figures. We are grateful to Dr. YR Yadav for his permission to use the tubular retractor figure. The authors would also like to acknowledge Mr. Harshal Kharkar for his efforts in editing the figures. 


\section{Authors' contributions}

Made substantial contributions to conception and design of the study and performed data analysis and interpretation, performed data acquisition, as well as provided administrative, technical, and material support: Shaikh S, Deopujari C

\section{Availability of data and materials}

Not applicable.

\section{Financial support and sponsorship}

None.

\section{Conflicts of interest}

All authors declared that there are no conflicts of interest.

\section{Ethical approval and consent to participate}

Not applicable.

\section{Consent for publication}

Not applicable.

\section{Copyright}

(c) The Author(s) 2020.

\section{REFERENCES}

1. Fries G, Perneczky A. Intracranial endoscopy. Adv Tech Stand Neurosurg 1999;25:21-60.

2. Rigante L, Borghei-Razavi H, Recinos PF, Roser F. An overview of endoscopy in neurologic surgery. Cleve Clin J Med 2019;86:16ME-24.

3. Marcus HJ, Cundy TP, Hughes-Hallett A, Yang GZ, Darzi A, Nandi D. Endoscopic and keyhole endoscope-assisted neurosurgical approaches: a qualitative survey on technical challenges and technological solutions. Br J Neurosurg 2014;28:606-10.

4. Abbott R. History of neuroendoscopy. Neurosurg Clin N Am 2004;15:1-7.

5. Engel RM. Philipp Bozzini--the father of endoscopy. J Endourol 2003;17:859-62.

6. Herr HW. Max Nitze, the cystoscope and urology. J Urol 2006;176:1313-6.

7. Decq P, Schroeder HW, Fritsch M, Cappabianca P. A history of ventricular neuroendoscopy. World Neurosurg 2013;79:S14.e1-6.

8. Linder TE, Simmen D, Stool SE. Revolutionary inventions in the 20th century. The history of endoscopy. Arch Otolaryngol Head Neck Surg 1997;123:1161-3.

9. Fukushima T, Ishijima B, Hirakawa K, Nakamura N, Sano K. Ventriculofiberscope: a new technique for endoscopic diagnosis and operation. Technical note. J Neurosurg 1973;38:251-6.

10. Decq P, Brugieres P, Le Guerinel C, Djindjian M, Keravel Y, Nguyen JP. Percutaneous endoscopic treatment of suprasellar arachnoid cysts: ventriculocystostomy or ventriculocystocisternostomy? Technical note. J Neurosurg 1996;84:696-701.

11. Decq P, Le Guerinel C, Brugières P, et al. Endoscopic management of colloid cysts. Neurosurgery 1998;42:1288-94; discussion 1294-6.

12. Jimenez D, Endoscopes and instrumentation. Neuroendoscopic Instruments and Surgical Technique. In: Jimenez D, editor. Endoscopic neurological surgery. New Delhi: Jaypee Brothers; 2019. pp. 16-26.

13. Agrawal V, Aher RB. Endoluminal shuntscope-guided ventricular catheter placement: early experience. Asian J Neurosurg 2018;13:1071-3.

14. Kestle JR, Drake JM, Cochrane DD, et al; Endoscopic Shunt Insertion Trial participants. Lack of benefit of endoscopic ventriculoperitoneal shunt insertion: a multicenter randomized trial. J Neurosurg 2003;98:284-90.

15. Schroeder HW, Oertel J, Gaab MR. Endoscopic treatment of cerebrospinal fluid pathway obstructions. Neurosurgery 2007;60:ONS44-51; discussion ONS51-2.

16. Schroeder HW. A new multipurpose ventriculoscope. Neurosurgery 2008;62:489-91; discussion 491-2.

17. Schroeder HW, Nehlsen M. Value of high-definition imaging in neuroendoscopy. Neurosurg Rev 2009;32:303-8; discussion 308.

18. Hellwig D, Benes L, Bertalanffy H, Bauer BL. Endoscopic stereotaxy--an eight year's experience. Stereotact Funct Neurosurg 1997;68:90-7.

19. Perneczky A, Fries G. Endoscope-assisted brain surgery: part 1--evolution, basic concept, and current technique. Neurosurgery 1998;42:219-24; discussion 224-5.

20. Grunert P, Perneczky A, Resch K. Endoscopic procedures through the foramen interventriculare of Monro under stereotactical conditions. 
Minim Invasive Neurosurg 1994;37:2-8.

21. Limbrick DD Jr, Baird LC, Klimo P Jr, Riva-Cambrin J, Flannery AM; Pediatric Hydrocephalus Systematic Review and Evidence-Based Guidelines Task Force. Pediatric hydrocephalus: systematic literature review and evidence-based guidelines. Part 4: Cerebrospinal fluid shunt or endoscopic third ventriculostomy for the treatment of hydrocephalus in children. J Neurosurg Pediatr 2014;14 Suppl 1:30-4.

22. Hellwig D, Grotenhuis JA, Tirakotai W, et al. Endoscopic third ventriculostomy for obstructive hydrocephalus. Neurosurg Rev 2005;28:134; discussion 35-8.

23. Darbar A, Kim PD, Yusopov I, Krishnamurthy S. Use of Grotenhuis perforator in endoscopic third ventriculostomy and cyst fenestration. Minim Invasive Neurosurg 2008;51:126-9.

24. Labidi M, Lavoie P, Lapointe G, et al. Predicting success of endoscopic third ventriculostomy: validation of the ETV Success Score in a mixed population of adult and pediatric patients. J Neurosurg 2015;123:1447-55.

25. Deopujari CE, Karmarkar VS, Shaikh ST. Endoscopic third ventriculostomy: success and failure. J Korean Neurosurg Soc 2017;60:306-14.

26. Raju S, Ramesh S. Endoscopic third ventriculostomy through lamina terminalis: a feasible alternative to standard endoscopic third ventriculostomy. Neurol India 2016;64:75-80.

27. Oppido PA, Fiorindi A, Benvenuti L, et al. Neuroendoscopic biopsy of ventricular tumors: a multicentric experience. Neurosurg Focus 2011;30:E2.

28. Souweidane MM, Luther N. Endoscopic resection of solid intraventricular brain tumors. J Neurosurg 2006;105:271-8.

29. Barber SM, Rangel-Castilla L, Baskin D. Neuroendoscopic resection of intraventricular tumors: a systematic outcomes analysis. Minim Invasive Surg 2013;2013:898753.

30. Jankowski R, Auque J, Simon C, Marchal JC, Hepner H, Wayoff M. Endoscopic pituitary tumor surgery. Laryngoscope 1992;102:198202.

31. Jho HD, Carrau RL. Endoscopic endonasal transsphenoidal surgery: experience with 50 patients. $J$ Neurosurg 1997;87:44-51.

32. Cappabianca P, Alfieri A, de Divitiis E. Endoscopic endonasal transsphenoidal approach to the sella: towards functional endoscopic pituitary surgery (FEPS). Minim Invasive Neurosurg 1998;41:66-73.

33. Kassam AB, Prevedello DM, Carrau RL, et al. Endoscopic endonasal skull base surgery: analysis of complications in the authors' initial 800 patients. J Neurosurg 2011;114:1544-68.

34. Dusick JR, Esposito F, Kelly DF, et al. The extended direct endonasal transsphenoidal approach for nonadenomatous suprasellar tumors. J Neurosurg 2005;102:832-41.

35. Locatelli D, Karligkiotis A, Turri-zanoni M, Canevari FR, Pozzi F, Castelnuovo P. Endoscopic endonasal approaches for treatment of craniovertebral junction tumours. In: Visocchi M, editor. New trends in craniovertebral junction surgery. Cham: Springer International Publishing; 2019. pp. 209-24.

36. Oi S, Samii A, Samii M. Frameless free-hand maneuvering of a small-diameter rigid-rod neuroendoscope with a working channel used during high-resolution imaging. Technical note. J Neurosurg 2005;102:113-8.

37. Grotenhuis A. Neuroendoscopic instruments and surgical technique. In: Sgouros S, editor. Neuroendoscopy - current status and future trends. Berlin, Heidelberg: Springer; 2014. pp. 81-91.

38. Inoue $\mathrm{D}$, Yoshimoto $\mathrm{K}$, Uemura $\mathrm{M}$, et al. Three-dimensional high-definition neuroendoscopic surgery: a controlled comparative laboratory study with two-dimensional endoscopy and clinical application. J Neurol Surg A Cent Eur Neurosurg 2013;74:357-65.

39. Destandau J. A special device for endoscopic surgery of lumbar disc herniation. Neurol Res 1999;21:39-42.

40. Chiu JC. Endoscopic assisted lumbar microdecompressive spinal surgery with a new SMART endoscopic spine system. Surg Technol Int 2006;15:234-41.

41. Oertel JM, Mondorf Y, Gaab MR. A new endoscopic spine system: the first results with "Easy GO". Acta Neurochir (Wien) 2009; 151:1027-33.

42. Cappabianca P, Cavallo LM, de Divitiis E. Endoscopic endonasal transsphenoidal surgery. Neurosurgery 2004;55:933-40; discussion 940-1.

43. Locatelli D, Canevari FR, Acchiardi I, Castelnuovo P. The endoscopic diving technique in pituitary and cranial base surgery: technical note. Neurosurgery 2010;66:E400-1; discussion E401.

44. Lekovic GP, Gonzalez LF, Feiz-Erfan I, Rekate HL. Endoscopic resection of hypothalamic hamartoma using a novel variable aspiration tissue resector. Neurosurgery 2006;58:ONS166-9; discussion ONS166-9.

45. Hiraishi M, Konisi T, Miyama T, et al. KTP laser and its clinical application: for the endoscopic treatment. J Jap Sac Laser Med 1990;11:425-8.

46. Vandertop WP, Verdaasdonk RM, van Swol CF. Laser-assisted neuroendoscopy using a neodymium-yttrium aluminum garnet or diode contact laser with pretreated fiber tips. J Neurosurg 1998;88:82-92.

47. Calisto A, Dorfmüller G, Fohlen M, Bulteau C, Conti A, Delalande O. Endoscopic disconnection of hypothalamic hamartomas: safety and feasibility of robot-assisted, thulium laser-based procedures. J Neurosurg Pediatr 2014;14:563-72.

48. Willems PW, Vandertop WP, Verdaasdonk RM, van Swol CF, Jansen GH. Contact laser-assisted neuroendoscopy can be performed safely by using pretreated "black" fibre tips: experimental data. Lasers Surg Med 2001;28:324-9.

49. Oertel J, Krauss JK, Gaab MR. Ultrasonic aspiration in neuroendoscopy: first results with a new tool. J Neurosurg 2008;109:908-11.

50. Cinalli G, Imperato A, Mirone G, et al. Initial experience with endoscopic ultrasonic aspirator in purely neuroendoscopic removal of intraventricular tumors. J Neurosurg Pediatr 2017;19:325-32.

51. Dlouhy BJ, Dahdaleh NS, Greenlee JD. Emerging technology in intracranial neuroendoscopy: application of the NICO Myriad. Neurosurg Focus 2011;30:E6.

52. McLaughlin N, Ditzel Filho LF, Prevedello DM, Kelly DF, Carrau RL, Kassam AB. Side-cutting aspiration device for endoscopic and 
microscopic tumor removal. J Neurol Surg B Skull Base 2012;73:11-20.

53. Nduom EK, Sribnick EA, Ormond DR, Hadjipanayis CG. Neuroendoscopic resection of intraventricular tumors and cysts through a working channel with a variable aspiration tissue resector: a feasibility and safety study. Minim Invasive Surg 2013;2013:471805.

54. Mohanty A, Thompson BJ, Patterson J. Initial experience with endoscopic side cutting aspiration system in pure neuroendoscopic excision of large intraventricular tumors. World Neurosurg 2013;80:655.e15-21.

55. Rohde V, Behm T, Ludwig H, Wachter D. The role of neuronavigation in intracranial endoscopic procedures. Neurosurg Rev 2012;35:351-8.

56. Esposito F, Di Rocco F, Zada G, et al. Intraventricular and skull base neuroendoscopy in 2012: a global survey of usage patterns and the role of intraoperative neuronavigation. World Neurosurg 2013;80:709-16.

57. Krombach GA, Rohde V, Haage P, Struffert T, Kilbinger M, Thron A. Virtual endoscopy combined with intraoperative neuronavigation for planning of endoscopic surgery in patients with occlusive hydrocephalus and intracranial cysts. Neuroradiology 2002;44:279-85.

58. Coelho G, Kondageski C, Vaz-Guimarães Filho F, et al. Frameless image-guided neuroendoscopy training in real simulators. Minim Invasive Neurosurg 2011;54:115-8.

59. Ashour AM, Elbabaa SK, Caputy AJ, Gragnaniello C. Navigation-guided endoscopic intraventricular injectable tumor model: cadaveric tumor resection model for neurosurgical training. World Neurosurg 2016;96:261-6.

60. Auer LM. Ultrasound stereotaxic endoscopy in neurosurgery. In: Bauer BL, Hellwig D, editors. Minimally Invasive Neurosurgery I. Vienna: Springer; 1992. pp. 34-41.

61. Yamakawa K, Kondo T, Yoshioka M, Takakura K. Ultrasound guided endoscopic neurosurgery--new surgical instrument and technique. Acta Neurochir Suppl 1994;61:46-48.

62. Resch KD. Endo-neuro-sonography: first clinical series (52 cases). Childs Nerv Syst 2003;19:137-44.

63. Strowitzki M, Kiefer M, Steudel WI. A new method of ultrasonic guidance of neuroendoscopic procedures. Technical note. J Neurosurg 2002;96:628-32.

64. Chartrain AG, Hom D, Bederson JB, Mocco J, Kellner CP. Intracavitary ultrasound (ICARUS): a neuroendoscopic adaptation of intravascular ultrasound for intracerebral hemorrhage evacuation. J Neurointerv Surg 2018;10:e16.

65. Di Somma A, Narros Gimenez JL, Almarcha Bethencourt JM, Cavallo LM, Márquez-Rivas J. Neuroendoscopic intraoperative ultrasoundguided technique for biopsy of paraventricular tumors. World Neurosurg 2019;122:441-50.

66. Yamasaki T, Moritake K, Akiyama Y, Oi S. Microvascular doppler ultrasound-assisted neuroendoscopic surgery. Br J Neurosurg 2000;14:464-7.

67. Yamasaki T, Moritake K, Nagai H, Kimura Y. Integration of ultrasonography and endoscopy into transsphenoidal surgery with a "picturein-picture" viewing system--technical note. Neurol Med Chir (Tokyo) 2002;42:275-7; discussion 278.

68. McLaughlin N, Prevedello DM, Engh J, Kelly DF, Kassam AB. Endoneurosurgical resection of intraventricular and intraparenchymal lesions using the port technique. World Neurosurg 2013;79:S18.e1-8.

69. Sharif S, Shaikh MY, Ali SM. Novel tool for minimally invasive brain surgery-syringe port system. World Neurosurg 2019;131:339-45.

70. Yadav YR, Yadav S, Sherekar S, Parihar V. A new minimally invasive tubular brain retractor system for surgery of deep intracerebral hematoma. Neurol India 2011;59:74-7.

71. Chandra PS, Kaur KD. Development of a unique retractor for performing endoscopic pituitary surgery-EASYTRAC. Neurol India 2019;67:1509-12.

72. Hong CS, Prevedello DM, Elder JB. Comparison of endoscope- versus microscope-assisted resection of deep-seated intracranial lesions using a minimally invasive port retractor system. J Neurosurg 2016;124:799-810.

73. Cappabianca P, Esposito F, Esposito I, Cavallo LM, Leone CA. Use of a thrombin-gelatin haemostatic matrix in endoscopic endonasal extended approaches: technical note. Acta Neurochir (Wien) 2009;151:69-77; discussion 77.

74. Yao HH, Hong MK, Drummond KJ. Haemostasis in neurosurgery: what is the evidence for gelatin-thrombin matrix sealant? $J$ Clin Neurosci 2013;20:349-56.

75. Snyderman CH, Carrau RL, Prevedello DM, Gardner P, Kassam AB. Technologic innovations in neuroendoscopic surgery. Otolaryngol Clin North Am 2009;42:883-90.

76. Senger S, Antes S, Salah M, Tschan C, Linsler S, Oertel J. The view through the ventricle catheter - The new ShuntScope for the therapy of pediatric hydrocephalus. J Clin Neurosci 2018;48:196-202.

77. Manjila S, Mencattelli M, Rosa B, Price K, Fagogenis G, Dupont PE. A multiport MR-compatible neuroendoscope: spanning the gap between rigid and flexible scopes. Neurosurg Focus 2016;41:E13.

78. Friedman GN, Grannan BL, Nahed BV, Codd PJ. Initial experience with high-definition camera-on-a-chip flexible endoscopy for intraventricular neurosurgery. World Neurosurg 2015;84:2053-8.

79. Proctor MR. Endoscopic craniosynostosis repair. Transl Pediatr 2014;3:247-58.

80. Atroshi I, Hofer M, Larsson GU, Ornstein E, Johnsson R, Ranstam J. Open compared with 2-portal endoscopic carpal tunnel release: a 5-year follow-up of a randomized controlled trial. J Hand Surg Am 2009;34:266-72.

81. Gardner PA, Vaz-Guimaraes F, Jankowitz B, et al. Endoscopic endonasal clipping of intracranial aneurysms: surgical technique and results. World Neurosurg 2015;84:1380-93.

82. Zimmermann M, Krishnan R, Raabe A, Seifert V. Robot-assisted navigated neuroendoscopy. Neurosurgery 2002;51:1446-52.

83. Hoshide R, Calayag M, Meltzer H, Levy ML, Gonda D. Robot-assisted endoscopic third ventriculostomy: institutional experience in 9 patients. J Neurosurg Pediatr 2017;20:125-33.

84. De Benedictis A, Trezza A, Carai A, et al. Robot-assisted procedures in pediatric neurosurgery. Neurosurg Focus 2017;42:E7. 
85. Takasuna H, Goto T, Kakizawa Y, et al. Use of a micromanipulator system (NeuRobot) in endoscopic neurosurgery. J Clin Neurosci 2012;19:1553-7.

86. Mandel M, Petito CE, Tutihashi R, et al. Smartphone-assisted minimally invasive neurosurgery. J Neurosurg 2018;130:90-8.

87. Cavallo LM, Di Somma A, Solari D, de Divitiis O, Bracale UM, Cappabianca P. Preliminary experience with a new multidirectional videoendoscope for neuroendoscopic surgical procedures. PLoS One 2016;11:e0147524.

88. Di X, Sui A, Hakim R, Wang M, Warnke JP. Endoscopic minimally invasive neurosurgery: emerging techniques and expanding role through an extensive review of the literature and our own experience - part II: extraendoscopic neurosurgery. Pediatr Neurosurg 2011;47:327-36

89. Jaimovich SG, Bailez M, Asprea M, Jaimovich R. Neurosurgical training with simulators: a novel neuroendoscopy model. Childs Nerv Syst 2016;32:345-9.

90. Deopujari CE, Karmarkar VS, Shaikh ST, Gadgil US. Developing a dynamic simulator for endoscopic intraventricular surgeries. Childs Nerv Syst 2019;35:621-7. 